\title{
Plasma Exchange in a Patient with a Severe Viper Bite
}

\author{
A. Elmoqaddem ${ }^{1 *}$, N. Mrani Alaoui ${ }^{1}$, T. Cherrad. M. Hmidi ${ }^{1}$, F. Choumi ${ }^{2}$, K. Nadour ${ }^{2}$ \\ ${ }^{1}$ Anesthesiology and Intensive Care Department, Department of Emergency, Moulay Ismail Military Hospital, Meknes, Morocco \\ ${ }^{2}$ Faculty of Medicine, Sidi Mohamed Ben Abdellah University, Fes, Morocco
}

DOI: $10.36348 /$ sjmps.2021.v07i01.009

| Received: 14.10 .2020 | Accepted: 30.10 .2020 | Published: 16.01 .2021

*Corresponding author: A. Elmoqaddem

\section{Abstract}

This case report highlights the efficacy of Therapeutic Plasma Exchange in managing the post envenomation TMA, because Post snake bite renal failure due to thrombotic microangiopathy (TMA) is often overlooked and not considered as a separate entity while managing the patient.

Keywords: Plasma exchange, severe envenomation, viper bite.

Copyright () 2021 The Author(s): This is an open-access article distributed under the terms of the Creative Commons Attribution 4.0 International License (CC BY-NC 4.0) which permits unrestricted use, distribution, and reproduction in any medium for non-commercial use provided the original author and source are credited.

\section{INTRODUCTION}

We report a case of a severe viper bite in which plasma exchange was used as a means of therapy. We are discussing the value of plasmapheresis in snakebite envenomations.

A 43-year-old patient, a military professional practicing in Moroccan Western Sahara, with no previous Pathological history, was a victim of a viper bite next to the achilles tendon of the right lower limb. He was transferred to our ward on the third day of the bite because of his worse clinical condition. On admission, the patient was conscious, anxious, eupneic, afebrile, with stable hemodynamic status.

The examination found a hot, tense, swollen right lower limb with a diffuse bruising of the limb extended to the right lower half of the body with diffuse pain, foot and posterior tibial pulses were present.

The laboratory tests found urea at $0.025 \mathrm{mmol}$ / 1 , creatinine at 0.12 micromole / 1 hemoglobin at $10 \mathrm{~g} /$ $\mathrm{dl}$, level platelets at 18,000 elts / $\mathrm{mm} 3$, TP at 26\%, TCA at one and a half times the control, fibrinogen at $0.7 \mathrm{~g} / 1$ with presence of PDF and soluble complexes.

The fasciotomy was not performed. The initial resuscitation included a vascular filling with crystalloids and a four fresh frozen plasma (PFC) transfusion, analgesia morphine by titration and antiulcer prophylaxis (omeprazole). Antibiotic therapy (penicillin A / acid clavulanic and metronidazole) was prescribed and anti-tetanus serum as well as a vaccination booster tetanus administered. Anti-venom serum was not used due to its unavailability.

A first plasma exchange session was performed six hours after admission and clearing with albumin and PFC. Clinical improvement and biological was noted the next day: reduced edema and less stretched limb; platelets went up to 50,000 elts / $\mathrm{mm} 3$, $\mathrm{TP}$ at $39 \%$ and fibrinogen at $1.70 \mathrm{~g} / 1$.

A second session of plasmapheresis was performed on the second day of admission. On the third day we noted a very clear improvement with a TP at $65 \%$, a platelet count at 87,000 elts/ $\mathrm{mm} 3$, a fibrinogen level at $2.27 \mathrm{~g} / \mathrm{L}$ and normalization of renal function. On the fifth day of hospitalization, there was a reduction in the bruise with disappearance of the edema, the limb becomes free, the PT goes to $90 \%$ and the platelets to 133,000 elts / $\mathrm{mm} 3$ and fibrinogen at $3 \mathrm{~g}$ / 1. and the patient was transferred to the medical department.

Snake bite is the most serious form of envenomation and is responsible of $4 \%$ of deaths in Morocco.

Snake venoms are made up of a collection of protein enzymes (toxins). Snake venom can be divided into three groups: cytotoxic (Viperidae), neurotoxic (Elapidae) and hematotoxic (Colubridae).

The cytotoxic effect can lead to localized pain, edema and tissue necrosis with possible coagulopathy, hypovolemic shock, renal failure and death. 
A. Elmoqaddem et al., Saudi J Med Pharm Sci, Jan, 2021; 7(1): 50-51

The neurotoxic effect can be manifested by drowsiness, visual disturbances and respiratory distress.

Haematological toxicity manifests itself usually with bleeding that can quickly progress to DIC [1].

The behavior to be taken in the face of a snakebite, which has been the subject of recent development, is based on administration of antivenom immunotherapy, the only specific and effective treatment insevere envenomation [2]. But the number of antivenoms available worldwide is declining.

Successful applications of plasmapheresis in snakebite victims have been reported. The role of plasmapheresis in the management of envenomation has been explored in snakebite victims to remove venom toxins from the blood and was used to treat 24 snakebite patients [3].

Other studies also report the effectiveness of plasmapheresis in the treatment of envenomation by bite snake complicated with coagulopathies.

However, plasmapheresis did not provide any benefit in three patients who suffered from a bone bite.Malayan krait snakes (Bungarus candidus) [4]. This failure may be due to the rapid diffusion of the effect.neurotoxic in the venom [4].

In addition to the elimination of the venom circulating in the blood, plasmapheresis would also eliminate the toxins diffused into extravascular spaces and target organs after redistribution phenomenon [5].

In our case, given the unavailability of antivenom serum in our ward, plasmapheresis was performed.

A clinical and haematological improvement was noted from the first session, with a favorable evolution, despite the delay between envenomation and plasma exchange. The duration of hospitalization in intensive care was five days and no intervention on the limb was necessary.

However, the effectiveness of plasmapheresis remains debatable. One important question that should be asked here is: is it the plasmapheresis that is responsible for the clinical improvement or this is just the normal course of viper envenomation?

The short stay in hospital, minimal serious complications and limb preservation in victims of Snakebites support the use of plasmapheresis [5]. She could represent an interesting alternative in the absence of antivenom, but prospective studies versus control cases are necessary in order to clarify the benefit of plasmapheresis in severe envenomation by bite of snake.

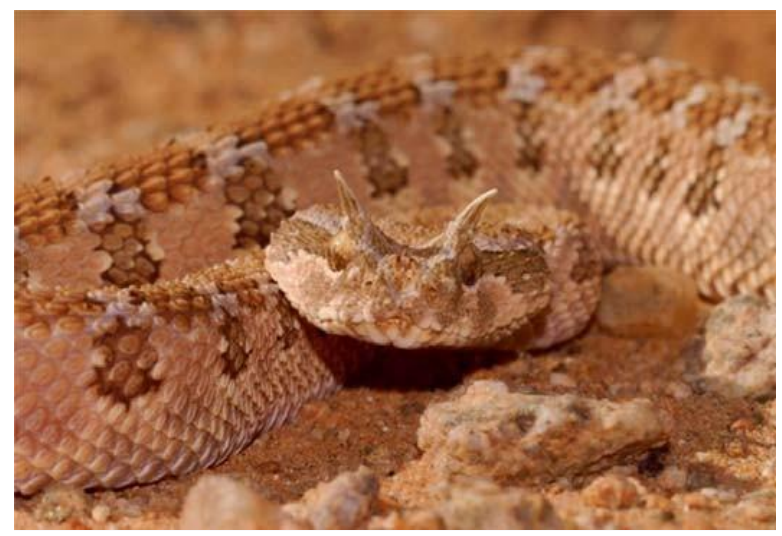

Saharan horned viper (cerastes cerastes)

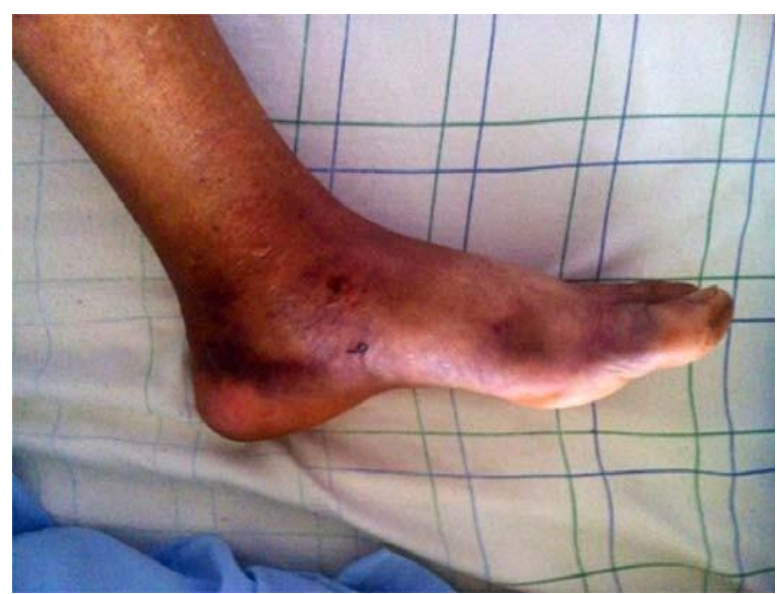

Picture of the patient's foot showing the bitten area. The mark of the two hooks is evident with ecchymotic and edematous plaques on foot

\section{REFERENCES}

1. Pantanowitz, L., \& Andrzejewski, C. (2006). Plasma exchange therapy for victims of envenomation: is this reasonable? Journal of clinical apheresis, 21(4), 215-218.

2. Larreche, S., Mion, G., Clapson, P., Debien, B., Wybrecht, D., \& Goyffon, M. (2008). Ophidian neurotoxins. Ann Fr Anesth Reanim. 27:310-316.

3. Rasulov, A. R., \& Berdymuradov, D. B. (1994). Intensive therapy in bites of poisonous snakes. Anesteziologiia i reanimatologiia, (3), 5960.

4. Laothong, C., \& Sitprija, V. (2001). Decreased parasympathetic activities in Malayan krait (Bungarus candidus) envenoming. Toxicon, 39(9), 1353-1357.

5. Yildirim, C., Bayraktaroğlu, Z., Gunay, N., Bozkurt, S., Köse, A., \& Yilmaz, M. (2006). The use of therapeutic plasmapheresis in the treatment of poisoned and snake bite victims: an academic emergency department's experiences. Journal of clinical apheresis, 21(4), 219-223. 